\title{
Determinant Variables behind Motorcyclist Daily Favored Speed
}

\author{
Don G. N. da Cost, Siti Malkhamah, and Latif B. Suparma
}

\begin{abstract}
Unbalanced in mobility and safety is a latent issue because although speeding has been associated with fatal crash but excessive speed without having been punished still occurs. This study focuses on how to bridge it by identifying the reason, triggering variables and explanatory variables of speeding behavior comprehensively. A number 159 of participants which is the same monitored motorcyclist participated in braking maneuver test was successfully interviewed. Their answer was analyzed using structural equation model. The results showed that: 1) speed choice was caused by trip purpose and triggered by rider's perception about their braking and hazard detection ability, and level of familiarity with road, traffic and vehicle characteristics as well 2) such perception was built due to their riding frequency, meanwhile, that the age does not influence it is an interesting issue because it indicates that speeding behavior is customary to be a commonly matter. Moreover, speeding is an intentional risk taking behavior as riders accepted both potential advantages and possible disadvantages gained from speeding. Therefore, the required speed management, rider's perception improvement, and the consequential implication due to the result of this study was discussed, including how to intervene such perception based on education, engineering and enforcement approaches.
\end{abstract}

Index Terms—Motorcyclist, Speed choice, Speeding behavior.

\section{INTRODUCTION}

SPEEDING has been commonly known to be the primary $N_{\text {factor associated with crashed and/or fatal crash }}$ probability [1], [2]. However, excessive speed without having been punished habitually occurred in many developing countries, including Indonesia [3]. According to [4], each risky situation produced by behavioral factors could be explained by identifying all potential determinant variables

Don G. N. da Cost is now with Ph.D. Student, Department of Civil and Environmental Engineering, Faculty of Engineering, Universitas Gadjah Mada, Jl. Grafika No.2, 55281, Yogyakarta, Indonesia(dnoesaku@gmail.com).

Latif B. Suparma is with Department of Civil and Environmental Engineering, Faculty of Engineering, Universitas Gadjah Mada, Jl. Grafika No.2, 55281, Yogyakarta, Indonesia.

Siti Malkhamah is with Department of Civil and Environmental Engineering, Faculty of Engineering, Universitas Gadjah Mada, Jl. Grafika No.2, 55281, Yogyakarta, Indonesia behind it, i.e., including attitudes, motivation and perception, as well as their descriptive variables such as age, gender, experience, etc. A number of previous concerned studies have reported that speeding behavior was caused by trip purposes (motivation) related to a number of social-economic advantages, i.e., mostly by time saving and sensation seeking devices [5], [6], and triggered by riders' perception about their braking and hazard detection ability, as well as due to their level of familiarity with road, traffic and vehicle conditions [4]-[7] which might be vary due to a differences in age, gender, education, and riding experience [8].

On the other hand, although braking capability has been also reported played important role in accident occurrence [9]-[11] and accident consequence [1], [2], [12] as well, but thus far braking capability and variable that influence it has not been taking into account in the speed limit determination and/or driving licensing program. The existing speed limit determination has been relied on the effect of road geometry, traffic composition and/or road environmental aspects [1], [2], [13], rather than those human factors; whilst the practical-skill section of the safety-riding program was more focused on how to ride and brake safely [14]. Accordingly, it is thought that exceeding speed limit might occur due to unbalanced situation between riders' mobility expectancy (social-economic needs such as for time saving and sensation seeking purposes) and safety support system matter (appropriate speed limit, standardized braking capability) [15]. Therefore, the correlation between speeding behavior and accident risk based on human behavioral factor should be further investigated. In this particularly case, it is required to identify not only the reason of speeding (why it occurs) but also what is their triggering and explanatory variables, in accord with [4].

It is an urgent agenda because, thus far, most of previous studies were partially focused on the single effect of road (infrastructure, or geometrical design), road environment (road side feature, or side friction) [8], use of the in-vehicle tools (braking system (antilock braking system/ABS, or electronic stability control/ESC) [16], or main and braking lighting, or passenger protective tools), or human factor (age, or gender, or riding skill, or perception) [4], [7], [8] to accident probability and/or consequences. For example: enjoying the sensation gained from speeding, or driving fast to save travel time were the most well-known reasons of speeding behavior [5]. However, the reasons behind it and/or their explanatory variables have not been sufficiently explored as a cumulative factor so that the produced information has never been conducted in a synchronized mass-action plan concurrently. 
Consequently, the previous recommendation obtained from such partial approach methods or safety program might not produce an optimum result [14] due to incomplete information, or inappropriate method, and/or inadequate accident risk management strategy and/or techniques.

This study focuses on how to bridge it, particularly how to build a comprehensive and appropriate accident risk management strategy based on the effect of human factor, i.e., by correlating the reason and the triggering variables of speeding behavior as well as their explanatory variables, with their crash avoidance ability due to their riding skill, which in this study was considered based on their braking ability. Further, by comparing their mean braking ability with predicted braking distance reported by [11], the accident probability and/or possible consequences might be described so that it could be used to recommend better appropriate and contextual accident risk management strategy and/or techniques, and could be simultaneously executed more easily. In turn, by intervening appropriate strategy and/or techniques based on riders' perception and riding awareness improvement, accident number and/or fatal crash probability might be reduced more progressively because it is thought that miss-perception about riding skill and/or accident risk could result in riders' inappropriate speed chosen.

\section{STUDY DESIGN}

Since human behavioral factor, particularly in relationship with determinant variables that influence speeding behavior, would be confronted with their crash avoidance ability based on their braking performance, a self-reported interview using questionnaire and a braking maneuver test on dry, level and good pavement surface conditions were undertaken consecutively. First, they were asked to participate in braking maneuver test and right after then they fulfil the concerned questionnaire. The braking maneuver test was conducted under an expected condition scheme, where although participants have no idea when the stop sign would be given during they travel with their daily favored speed $(\mathrm{V})$, but they knew that they have to apply a hard braking force immediately after the stop sign was recognized. Their actual braking distance (S), i.e., the distance needed since their rear brake's lamp was flashed on until the vehicle completely stop. then was measured and subsequently by using braking distance's equation recommended by AASHTO [17], their actual braking deceleration rates (a) could be determined easily.

By using this data collection scheme, the result of braking maneuver test (hard braking deceleration rate) could be compared with their perception because from the obtained braking deceleration rates, braking capability could be classified into below average, average and above average categories based on its standard deviation value. Thus, riders' perception about their braking capability could be simply discussed and evaluated, particularly in relationship with accident probability and/or consequence due to the differences in potential produced braking distance. It could be investigated because previous study reported that accident probability might be determined using safety factor, i.e. the ratio between sight distance and stopping distance [18], or between available stopping sight distance (ASSD) to minimum stopping sight distance (MSSD) [15].

A number of 159 of volunteers were successfully recruited to participate in questionnaire fulfillment. They were the same monitored riders who participated in the braking maneuver test. The aim of the braking maneuver test is to classify motorcyclist hard braking deceleration rate, whilst the substance of the questionnaire is about riders' perception about their daily favored speed and the reasons behind it. The obtained braking deceleration rate then was used to predict braking distance by using the result of a previous concerned study's finding [11]. Such predicted braking distance then was used to determine a minimum stopping sight distance (SSD) using AASHTO's model [17]. The predicted stopping sight distance (PSSD) then was compared with the available stopping distance at un-signalized intersection, reflected in critical distance headway $(\mathrm{CDH})$, i.e., the average minimum acceptable upstream distance between major stream vehicle and the potential conflict point (well known as postencroachment distance/PED) due to entering/exiting vehicle to/from minor road [19]. The result then was referred to as safety factor (SF), which could be used to assess accident probability [15], [18]. If the ratio between the CDH and PSSD is less than 1.0 then a crash might be occurred, whilst its consequence is determined using a predicted impact speed [2]. In addition, speed choices categories would be classified into below average, average and above average so that the correlation between the reason of speeding of each driver's categories and its own potential risk due to their braking capability could be further investigated.

Subsequently, the observed variables investigated through questionnaire were: their daily favored speed choice (on wet $\left(\mathrm{X}_{9}\right)$ and dry $\left(\mathrm{X}_{8}\right)$ conditions), factors that influence it (time saving $\left(\mathrm{X}_{7}\right)$, sensation seeking $\left(\mathrm{X}_{6}\right)$ ), variables that might trigger it (braking capability $\left(\mathrm{X}_{5}\right)$, hazard detection ability $\left(\mathrm{X}_{4}\right)$, and level of familiarity with road, traffic and vehicle characteristics $\left(\mathrm{X}_{3}\right)$ ), and their explanatory variables (riding frequency $\left(\mathrm{X}_{2}\right)$, age $\left(\mathrm{X}_{1}\right)$ and gender $\left(\mathrm{X}_{0}\right)$ ). Further, the correlation between latent variables (risk factor, risk trigger and their descriptive variables) and their indicator variables as well as among such latent variables were analyzed using structural equation model (SEM). The input data was settled in 1 to 5 scales, and was analyzed using IBM-SPSS AMOSS 22 version. The goodness of fit is used to validate the model which describes the comparison between the model and data collected. The fit indices and indicator value for each type of statistical test are as follows [20]: 1) CMIN/df $<5,2) \mathrm{p}$-value $<0,05,3)$ RMSEA $<0,08,4)$ NFI and CFI between 0 and 1 , close to 1 is better 5) PFI $>0,5$. Also, from the model fit summary, the value of HOELTER was also usually used to describe the fit, i.e., it was accepted if it is greater than 200 , or if the probability level of default model is greater than 0.05 .

\section{RESULT AND DICUSSION}

\section{A. Factor behind the speeding behavior}


From the result of the interview it was found that, virtually, speeding behavior was hierarchal influenced by the following factors, consecutively: 1) risk factor, i.e., time saving and sensational seeking devices 2) risk trigger, which explained that time saving and sensation seeking devices are triggered by rider's perception about their braking and hazard detection capabilities, as well as their level of familiarity with road, traffic, and vehicle characteristics 3) descriptive variables, where riding frequency is the most influencer factor that effect such perceptions.

Accordingly, it could be established that risky attitude is influenced by motivation (trip purpose) and rider's perception about their braking and/or riding capabilities. However, this qualitative descriptive of such interview result could not describe the weak-strong correlation between latent variables and their explanatory variables as well as between such latent variables itself, so that the information produced could not be instantly used to be the basis of accident risk management due to rider's behavior. Therefore, by using the software application of IBM-SPSS AMOS version 22, the statistical multi-variety analysis was conducted using structural equation model (SEM).

As previously described, the substance of interview was focused on: 1) the reason of daily favored speed choice and/or exceeding the regulated speed limit 2) consideration used to be the basis of such risky behavior, i.e., in relationship with riders' perception about their braking and hazard detection abilities, as well as their level of familiarity with road, vehicle and traffic conditions. Subsequently, in order to assess the correlation between such perceptions and socio-demographic aspects, riders' age, gender and riding frequency were considered to be the explanatory variables. However, as the number of female participant which is successfully recruited was insufficient, i.e., only 12 persons from the total of recruited persons, so that gender $\left(\mathrm{X}_{0}\right)$ was eliminated from the speeding behavior structural model. Graphically, the structural model which describe the correlation between latent variables (risk factor, risk trigger and their descriptive variables), and between latent variable and their indicators can be seen in Figure 1 .

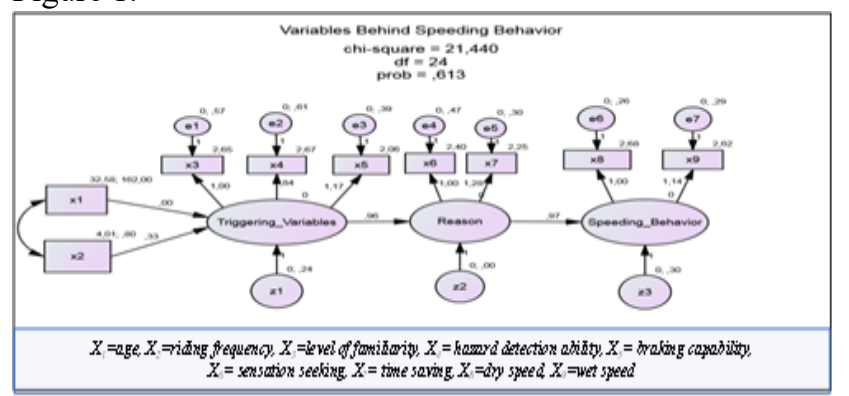

Fig. 1. The Correlation among Variables which Influenced Speed Choice

Statistically, from Figure 1 and the overall model fit test, it was shown that with a degree of freedom (df) of 24, the chisquare $\left(\chi^{2}\right)$ of default model was 21.440 , smaller than the standardized $\chi^{2}$ for level of significance $5 \%$, i.e., 36.415 . It means, the result of estimation obtained from the default model is suited to the collected sample data. The fit between such default model and data was also explained by the obtained probability level of 0.613 which is much greater than 0.05 . Subsequently, since the use of structural equation model was intended to also understand the correlation between latent variables and its indicator as well as among such latent variables itself, so that the explanation about whether the correlation was significant or not, can be found in Table I.

TABLE I

REGRESSION WIGHT FOR VARIABLE BEHIND SPEEDING BEHAVIOR MODEL

\begin{tabular}{|c|c|c|c|c|c|c|}
\hline & & Estimate & S.E. & C.R. & $P$ & Label \\
\hline Triggering_Variables & $<\times 2$ & ,328 & ,062 & 5,328 & $* * *$ & \\
\hline Triggering_Variables & $<\ldots \times 1$ &, 002 &, 003 &, 514 & ,607 & \\
\hline Reason & $<\ldots$ Triggering_Variables & ,956 & ,163 & 5,850 & $* * *$ & \\
\hline Speeding_Behavior & $<\ldots$ Reason &, 966 &, 162 & 5,955 & $* * *$ & \\
\hline $\mathrm{x} 3$ & $<$ <.. Triggering_Variables & 1,000 & & & & \\
\hline $\mathrm{x} 4$ & $<\ldots$ Triggering_Variables & ,837 &, 156 & 5,375 & $* * *$ & \\
\hline$x 5$ & <... Triggering_Variables & 1,174 & ,171 & 6,877 & $* * *$ & \\
\hline$x 6$ & $<$... Reason & 1,000 & & & & \\
\hline $\mathrm{x} 7$ & $<\ldots$ Reason & 1,281 &, 172 & 7,434 & $* * *$ & \\
\hline x8 & $<\ldots$ Speeding_Behavior & 1,000 & & & & \\
\hline $\mathrm{x} 9$ & $<\ldots$ Speeding Behavior & 1,141 & .133 & 8.607 & $* * *$ & \\
\hline
\end{tabular}

The estimate values in the Table 1 showed the covariance between latent variables and its indicators. Its significance was determined by $\mathrm{p}$-value. It can be seen that, except for $\mathrm{X}_{1}$ variable (riders' age), the p-values for each variable were less than 0.05 . This means that there is a significant correlation between latent variables and its builder indicators, and between one latent variable to the next latent variable. In other words, speeding behavior was evidently caused by time saving and sensational seeking devices, and triggered by riders' perceptions about their braking and hazard detection abilities as well as their familiarity with road, traffic and vehicle conditions; which were obtained through their riding frequency.

Besides, when Table II was compared with the indicator values of each fit indices' values obtained from AMOS it showed that all fit indices' values encountered with the acceptable criteria of each parameter. It showed the fitted model of variables behind speeding behavior.

TABLE II

OUTPUT ANALYSIS OF AMOSS

\begin{tabular}{|c|c|c|c|c|c|c|c|c|c|}
\hline $\begin{array}{c}\text { Fit } \\
\text { measures }\end{array}$ & $\begin{array}{c}\text { CMIN } \\
\chi^{2}\end{array}$ & $\mathrm{df}$ & $\begin{array}{c}\text { Prob } \\
\mathrm{p}\end{array}$ & $\chi^{2}$ /df & RMSEA & NFI & CFI & PNFI & $\begin{array}{c}\text { HOETLER } \\
0.05 ; 0.01\end{array}$ \\
\hline $\begin{array}{c}\text { Speeding } \\
\text { behavior } \\
\text { model }\end{array}$ & 21.440 & 24 & 0.613 & 0,893 & 0.000 & 0.951 & $\begin{array}{c}1.00 \\
0\end{array}$ & 0.634 & $269 ; 317$ \\
\hline Criteria & $\begin{array}{c}0< \\
\mathrm{CMIN}< \\
436.965\end{array}$ & $\begin{array}{c}0< \\
\mathrm{df} \\
<\end{array}$ & 0.05 & $<5$ & $<0.08$ & $>0.5$ & $>0.5$ & $>0.5$ & $>200$ \\
\hline
\end{tabular}

Accordingly, it could be inferred that, based on the selfinterview result, speeding behavior was virtually caused by trip purposes, i.e. for time saving and sensational seeking devices, similar with the result of a number of previous studies [4]-[7]. Such optional attitude was triggered by riders' perception about their braking and road hazard detection abilities as well as their level of familiarity with road, traffic and vehicle characteristics, which also similar with the findings of some previous concerned studies [4], [7]. 
Interestingly, such perception was much more influenced by riding frequency, rather than riders' age. This finding different with the previous concerned studies' results, reported that age was factor that associate with driving behavior [4], [7], [8], [21]. It strongly indicates that in Indonesia, speeding behavior is accepted to be a commonly matter because it has been done intentionally by most riders (both younger and older riders). Speeding was also can be referred to as an intentional risk taking behavior because riders did it to gain a number of social-economic advantages with any believes and/or selfconfidences in their braking and hazard detection abilities, and their level of familiarity with road, traffic and vehicle conditions as well. Therefore, rider's perception is the crucial factor that should be managed systematically.

From all previous description it could be concluded that: 1) speed choice was significantly influenced by trip purpose (time saving and enjoying the sensation), in accord with [4][7]; 2) risk trigger was built based on rider's perception about their braking and hazard detection ability, in accord with [4], [7], as well as their level of familiarity with road, traffic and vehicle characteristics, in accord with [22]; 3) riding frequency has a strong correlation with rider's perception about accident risk, meanwhile, that age does not influence it is an interesting issue because it unlike with previous findings [2], [4], [7]. This $3^{\text {rd }}$ conclusion might occur due to differences in trip purposes and/or social-control pattern

\section{B. Implication}

Speeding was indicated to be an intentional risk taking behavior where the risky behavior was triggered by perception obtained from riding frequency. However, their perception could be wrong because based on the predicted braking distance (BD) of $21 \mathrm{~m} \mathrm{[11]} \mathrm{and} \mathrm{the} \mathrm{predicted} \mathrm{critical} \mathrm{gap}$ acceptance (CGA) of $20 \mathrm{~m} \mathrm{[23],} \mathrm{the} \mathrm{safety} \mathrm{factor} \mathrm{(SF),} \mathrm{i.e.,}$ ratio of CGA to $\mathrm{BD}$ is less than 1.0. So it is worth to consider the effect of human behavioral factors in the future accident risk management devices. In this particularly case, the appropriate strategy and/or techniques could be built based on the possible intervened variables in each latent variables, i.e., trip purpose (reason of speeding), risk trigger (riders' perception) and explanatory variable (riding frequency). The reason of speeding, particularly for time saving purpose, is hard to be intervened because most Indonesian people use private vehicle, mostly motorcycle, to be their daily primary transport means and their commuter's daily trip was much influenced by the distance between their residence and work places as well as the concurrent mixed traffic conditions. On the other hand, there is no strict sanction against such traffic offence. Meanwhile, their riding frequency might be also difficult to be intervened, particularly based on pricing mechanism, because as previously mentioned, motorcycle was their daily primary transport means. Increasing fuel price is not a populist policy.

Hence, accident risk management intervention should be more focused on riders' perception. In this particularly case, it is thought that such perceptions could be improved through: 1) riders' experience in a seriously accident involvement, 2) safety education and/or training programs. However, the execution of such improvement should not be waited until an accident has been previously occurred. It has to be undertaken pro-actively because previous studies strongly indicate that some pro-active program could be implemented successfully, where such perception could be improved based on a combination effort on education, engineering and enforcement model, as it has been recommended by [2], [24]-[27]. The question is what kind of intervention that might be efficiently and appropriately applied? The following discussion might explain it.

Although when applying a driving license each rider has to complete a safety riding program including both knowledge and practical-skill items [14], [28]-[31], but there is no indications which explained the benefit gained from those items unless information about whether they passed the tests or not. For example: in the practical skill section, riders were asked to apply hard braking safely but they have never been communicated about the level of their braking capability, particularly in the relationship with their suitable speed choice suited to their braking ability. Riders need to know it exactly so that they could suite their daily favored speed choice progressively.

This is an important and urgent matter because: 1) from the educational point of view, good attitude (riding behavior) might be built if there is adequate information about the effect of their risky behavior in relationship with their actual riding skill. Speed choice should be deal with braking ability. 2) From engineering aspects, appropriate effort which bridging riders mobility expectancy (daily favored speed choice) and their safety riding ability, such as the use of the right types of braking and/or proper braking technology, is insufficient. Again, it could be bridged by informing all riders about their appropriate speed which is suited to their level of braking ability. 3) Excessive speed limit and/or riding in inappropriate speed is a commonly view in many countries and still occur continuously, even without having been punished. Accordingly, if there is a standardized braking capability that could be used to determine a more appropriate speed limit, then the authorities could strictly punish traffic offender more easily. Presently the question is: how to integrate those educational, engineering and enforcement task into a strategic safety program?

In order to answer it, it is noteworthy that, as previously mentioned, daily favored speed was chosen due to riders' overconfidence in their braking capability, whereas from $56 \%$ of riders who believe that their above average braking capability could help them avoid accident occurrence and/or fatal accident, only $24 \%$ of them could safely apply a high level of braking deceleration rate for a mean speed range of $50-60 \mathrm{~km} / \mathrm{h}$, i.e., above $8.7 \mathrm{~m} / \mathrm{s}^{2}$ (mean 6.57 , $\min 3.99$, $\max$ 12.8, std. dev. 2.12). The mean braking deceleration rate, virtually, similar with previous studies' report, i.e., around $5,65 \mathrm{~m} / \mathrm{s}^{2}$ [10], $6.6 \mathrm{~m} / \mathrm{s}^{2}$ [11] and $9.8 \mathrm{~m} / \mathrm{s}^{2}$ [12]. This phenomenon strongly indicates that such perception could be wrong. Therefore: 1) a high daily favored speed choice which was built based on such miss-perception should be avoided 2) meanwhile, braking capability should be improved. Such improvement is intended to reduce fatal crash probability because the higher the braking ability, the smaller the braking distance and the lower the impact speed; rather than to trigger 
risky behavior because at the same time, the authority should strictly punished speed limit offences.

The improvement of hard braking capability could be increased systematically by using rear and front brake concurrently and/or consecutively [9], where an increasing of braking deceleration rate of $2.07 \mathrm{~m} / \mathrm{s}^{2}$ could be achieved by novice rider through short time braking maneuver training [10]. The higher the braking ability, the shorter the produced stopping distance [11] so that riders with standardized braking capability have bigger opportunity to be avoided from accident and even when being involved in accident, they still have the bigger possibility to be avoided from fatal crash because according to [17] stopping distance has an inverse relationship with braking ability, exponentially.

Consequently, it is thought that the safety riding program should be improved by informing riders about their level of braking abilities and its consequences so that this initial awareness might reduce the possibility of speeding behavior and such risky behavior might be controlled more strictly because the speed limit determination has been undertaken based on a standardized braking capability. This study shows that such education, engineering and enforcement approaches model could be implemented concurrently so that an optimum result of accident risk management devices might be obtained. Hence, besides improving riders' perception about accident risk and their safety riding skill, it is also required to determine appropriate speed limit based on riders' standardized braking capability and their mobility expectancy.

Meanwhile on the other hand, some previous studies have also reported that after being involved in an accident without having a seriously suffered, a number of riders have a tendency to increase their level of risk taking behavior, such as speeding, due to accepted such accident consequences [21], [32], [33] to be a coincidence. This perception might be wrong because: 1) accident occurrence due to an intentional risk taking behavior was not a coincidence because whether they realize it or not, virtually, it was an intended behavior since they accepted its possible consequences 2) it should be aware that perception is a personality matter whilst accident is another as it involved other person or road user. In other words, perception might be right if riders exactly knew his/her riding ability as well as other road user's one. That is why it is required a standardized braking capability so that only riders with adequate riding skill would be allowed to drive their vehicles.

Accordingly, in order to ensure that such strategy and/or techniques could be successfully implemented, these following support systems might be required to manage the accident risk efforts, systematically and comprehensively:

1) Speed limit should be deal with standardized braking capability which could be obtained by improving the content of safety riding test (knowledge and practical-skill segments, which were the mandatory items that should be passed when applying a driving license), i.e., by integrating the effect of braking capability to accident probability and/or its possible consequences. Hence, riders have to be informed about the consequence of their level of braking ability in relationship with their daily favored speed choices and/or the regulated speed limit, and only driver with such safety riding competence might obtain the driving license.

2) However, the standardized braking capability could only be achieved if the pavement condition is respectable. Thus, it is needed to ensure that pavement condition, particularly at risky road segments such as un-signalized intersection, pedestrian crossing area, etc., should always be in well-preserved condition, in accord with [34].

In order to increase judicious law-enforcement, is required to increase public awareness about speeding consequence. Intentional speeding behavior might be worth to be considered and termed as a crime because it might trigger fatal crash. Such public awareness might be obtained from a creative, innovative and attractive media of traffic safety campaign, in accord with [35].

\section{CONCLUSION}

The results show that: 1) speed choice was influenced by trip purpose (time saving and enjoying the sensation) 2) risk trigger was built based on rider's perception about their braking and hazard detection ability as well as their level of familiarity with road, traffic and vehicle characteristics 3 ) Riding frequency had a strong correlation with rider's perception about accident probability and/or consequences. Meanwhile, that the age does not influence it is an interesting issue because it contrary with previous findings. This indicates that speeding behavior is accepted as a commonly matter so that it is worth to consider the effect of such human behavioral factor in the accident risk management devices, including how to intervene riders perception about accident probability, or when determining appropriate speed limit, as well as when improving driving licensing mechanism and criteria.

In addition, speeding behavior in Yogyakarta could be termed as intentional risk taking behavior because most riders accepted the potential advantages and might also possible disadvantages gained from speeding, triggered by perception obtained from riding frequency. Hence, driver's motivation, perception, and behavior (attitude) should be intervened by introducing more appropriate types of knowledge and practical-skill content in the driving licensing program, i.e., by communicating all new riders about their appropriate speed choice suited to their level of braking ability. This type of intervention does not need additional financial support because, virtually, the authorities already have closed circuit course to conduct practical-skill test so that it could be easily implemented.

\section{REFERENCES}

[1] DaCoTA, "Speed and Speed Management," 2013.

[2] WHO, "Speed management: a road safety manual for decisionmakers and practitioners.," Global Road Safety Partnership, Geneva, Switzerland, 2008.

[3] Y. O. Susilo, T. B. Joewono, and U. Vandebona, "Reasons underlying behaviour of motorcyclists disregarding traffic regulations in urban areas of Indonesia," Accid. Anal. Prev., vol. $75,2015$. 
[4] S. Joshi, T. Bellet, A. Banet, L. Robger, C. Turetscheck, R. Risser, J. Golias, G. Yannis, I. Spyropoulou, J. Carvalhais, L. Leden, J. Vasek, A. Delhaye, H. Robeboreck, G. Underwoord, and K. Humphrey, "Understanding risk taking behaviour within the context of PTW riders," Paris, 2010.

[5] C. F. Chen and C. W. Chen, "Speeding for fun? Exploring the speeding behavior of riders of heavy motorcycles using the theory of planned behavior and psychological flow theory," Accid. Anal. Prev., vol. 43, no. 3, pp. 983-990, 2011.

[6] J. T. Wong, Y. S. Chung, and S. H. Huang, "Determinants behind young motorcyclists' risky riding behavior," Accid. Anal. Prev., vol. 42, no. 1, pp. 275-281, 2010.

[7] P. Schroeder, L. Kostyniuk, and M. Mack, "2011 National Survey Of Speeding Attitudes and Behaviors," Washington DC, 2013.

[8] E. I. Vlahogianni, G. Yannis, and J. C. Golias, "Overview of critical risk factors in Power-Two-Wheeler safety," Accid. Anal. Prev., vol. 49, no. August 2015, pp. 12-22, 2012.

[9] W. Bartlett, A. Baxter, and N. Robar, "Motorcycle Braking test: I.P.T.M. Data Through 2006," Accid. Reconstr. J., vol. JulyAugus, no. -, pp. 19-21, 2007.

[10] M. Winkelbauer and K. Vavryn, "Braking Performance of Experienced and Novice Motorcycle Riders - Results of a Field Study," 2015.

[11] NSW.Gov, "Motorcycle ABS," 2012.

[12] A. Ueckermann, D. Wang, M. Oeser, and B. Steinauer, "Calculation of skid resistance from texture measurements," $J$. Traffic Transp. Eng. (English Ed., vol. 2, no. 1, pp. 3-16, 2015.

[13] Kementrian Perhubungan, Peraturan Menteri Perhubungan Nomor:111 Tahun 2015 tentang Tata Cara Penetapan Batas Kecepatan. Jakarta: Departemen Perhubungan Republik Indonesia, 2015

[14] P. Woratanarat, A. Ingsathit, P. Chatchaipan, and P. Suriyawongpaisal, "Safety riding program and motorcyclerelated injuries in Thailand," Accid. Anal. Prev., vol. 58, no. 2013, pp. 115-121, 2013.

[15] D. G. N. da Costa, S. Malkhamah, and L. B. Suparma, "Pengelolaan Risiko Kecelakaan Lalu Lintas: Cakupan, Indikator, Strategi dan Teknik," in Proceeding of the 2nd Symposium of The University Network for Indonesia Infrastructure Development, 2017, pp. 195-203.

[16] P. Cairney, "The Future of Skid Resistance?," in 3rd International Surface Friction Conference - Saving Lives, 2011, pp. 1-8.

[17] AASHTO, A Policy on Geometric Design of Highways and Streets, 2011 6th E. Washington DC: American Association of State Highway and Transportation Officials, 2011.

[18] T. Smith, S. Garet, and J. Cicchino, "The Effect of Sight Distance Training on the Visual Scanning of Motorcycle Riders: A Preliminary Look," Washington DC, 2013.

[19] L. Vasconcelos, A. B. Silva, G. Rouxinol, and A. Seco, "Estimation of Critical Headways at Unsignalized Intersections - A Microscopic Approach," in the 3rd International Conference on Road Safety and Simulation, 2011, pp. 1-18.

[20] D. M. P. Wedagama, "The Influence of Motorcyclists , Attitudes on Traffic Accidents and Offences," J. Tek. Sipil, vol. 24, no. 2, pp. 117-124, 2017.

[21] R. Ivers, T. Senserrick, S. Boufous, M. Stevenson, H. Y. Chen, M. Woodward, and R. Norton, "Novice drivers' risky driving behavior, risk perception, and crash risk: Findings from the DRIVE study," Am. J. Public Health, vol. 99, no. 9, pp. 16381644, 2009.

[22] D. G. N. da Costa, S. Malkhamah, and L. B. Suparma, "Motorcyclist risk taking behavior," in Proceeding of the 19th International Symposium of FSTPT, Islamic University of
Indonesia, 11-13 October 2016, ISBN: 979-95721-2-19, 2016, pp. 77-85.

[23] D. G. N. da Costa, S. Malkhamah, and L. B. Suparma, "A Systematic Approach in Developing An Accident Risk Reduction Scheme," in 6th International Annual Engineering Seminar.ISBN 978-1-5090-0741-7, 2016, pp. 13-18.

[24] J. Stikar, J. Hoskovec, and J. Smolikova, "Definition of System,” Stud. Psicol., vol. 50, no. 2, pp. 217-226, 2008.

[25] D. G. N. da Costa, "Accident Risk Analysis of Motorcyclist," in 15th International Symposium of the Indonesian Inter University Transport Studies Forum, 2012.

[26] V. Huth, E. Füssl, and R. Risser, "Motorcycle riders' perceptions, attitudes and strategies: Findings from a focus group study," Transp. Res. Part F Traffic Psychol. Behav., vol. 25, no. PART A, 2014.

[27] L. Dorn, Driver behaviour and training, vol. 3. 2008.

[28] Swedish Transport Agency, Driving licence - do you know what applies? transportstyrelsen.se. 2017.

[29] Arizona Governor's Office of Highway Safety, AN MSF Manual, Motorcycle Operator Manual, with supplementary information for three-wheel motorcycles. 2016.

[30] Idaho Transportation Department, Idaho Motorcycle Operator's Manual. Diviosion of Motor Vehicles, no. May. The Idaho Transportation Department Division of Motor Vehicles, 2015.

[31] M. Goodge, "Development of National Road Safety StrategyDriver Training \& Licensing. Kiribati Road Rehabilitation Project, Ministry of Public Works and Utilities, Contract KRRP/C/4," no. November, 2013.

[32] P. J. Knight, D. Iverson, and M. F. Harris, "Early driving experience and influence on risk perception in young rural people," Accid. Anal. Prev., vol. 45, pp. 775-781, 2012.

[33] H. Iversen, "Risk-taking attitudes and risky driving behaviour," Transp. Res., vol. 7, pp. 135-150, 2004.

[34] P. Cairney and A. Germanchev, "A pilot study of the effects of macrotexture on stopping distance," 2006.

[35] L. S. Putranto, "Pengaruh Media Kampanye Keselamatan Jalan terhadap Sikap Pengemudi Sepeda Motor. Kuliah Umum Jurusan Teknik Sipil Universitas Syah Kuala,” 2015. 